Check for updates

Cite this: RSC Adv., 2018, 8, 41740

Received 5th November 2018 Accepted 5th December 2018

DOI: $10.1039 / \mathrm{c} 8 \mathrm{ra} 09128 \mathrm{e}$

rsc.li/rsc-advances

\section{Solvothermal synthesis of $\mathrm{NiWO}_{4}$ nanostructure and its application as a cathode material for asymmetric supercapacitors $\dagger$}

\author{
Jinjun Tian, ${ }^{\mathrm{ab}}$ Yan Xue, ${ }^{\mathrm{b}}$ Xinping $\mathrm{Yu}^{\mathrm{a}}{ }^{\text {Y }}$ uanchao Pei, ${ }^{\mathrm{a}}$ Hucheng Zhang (D) *a \\ and Jianji Wang*a
}

\begin{abstract}
This study proposes a facile solvothermal synthesis of nickel tungstate $\left(\mathrm{NiWO}_{4}\right)$ nanowires for application as a novel cathode material for supercapacitors. The structure, morphology, surface area and pore distribution were characterized and their capacitive performances were investigated. The results showed that the $\mathrm{NiWO}_{4}$ nanowires synthesized in ethylene glycol solvent could offer a high specific capacitance of 1190 $\mathrm{F} \mathrm{g}^{-1}$ at a current density of $0.5 \mathrm{~A} \mathrm{~g}^{-1}$ and a capacitance retaining ratio of $61.5 \%$ within $0.5-10 \mathrm{~A} \mathrm{~g}^{-1}$. When used as a cathodic electrode of an asymmetric supercapacitor (ASC), the $\mathrm{NiWO}_{4}$ nanowire based device can be cycled reversibly in a high-voltage region of 0-1.7 $\mathrm{V}$ with a high specific capacitance of $160 \mathrm{~F} \mathrm{~g}^{-1}$ at $0.5 \mathrm{~A} \mathrm{~g}^{-1}$, which therefore contributed to an energy density of $64.2 \mathrm{~W} \mathrm{~h} \mathrm{~kg}^{-1}$ at a power density of $425 \mathrm{~W} \mathrm{~kg}^{-1}$. Moreover, $92.8 \%$ of its initial specific capacitance can be maintained after 5000 consecutive cycles $\left(5 \mathrm{~A} \mathrm{~g}^{-1}\right)$. These excellent capacitive properties make $\mathrm{NiWO}_{4}$ a credible electrode material for high-performance supercapacitors.
\end{abstract}

\section{Introduction}

With the ever-increasing energy consumption and the concomitant global warming and air pollution due to the over utilization of fossil fuels, clean and efficient energy storage devices have attracted unprecedented concern. ${ }^{1,2}$ Amongst the various energy devices, supercapacitors have received great attention by virtue of the high power density, charge-discharge rate, excellent cycling stability and environment friendliness. ${ }^{3,4}$ However, the major disadvantage of supercapacitors lies in their low energy density. So, more efforts have been devoted to the improvement of energy density without sacrificing their power density and cycle life.

Transition metal oxides/hydroxides such as $\mathrm{NiO},{ }^{5} \mathrm{Ni}(\mathrm{OH})_{2},{ }^{6}$ $\mathrm{Co}_{3} \mathrm{O}_{4}$ (ref. 7) are commonly employed faradic electrode material due to their low cost, low toxicity, and high specific capacity. Binary metal oxides $\mathrm{NiCo}_{2} \mathrm{O}_{4},{ }^{8} \mathrm{ZnCo}_{2} \mathrm{O}_{4},{ }^{9} \mathrm{CdMn}_{2} \mathrm{O}_{4}$ (ref. 10) and the related hydroxide electrode materials ${ }^{11}$ are reported to offer higher faradic capacitance relative to monometallic oxide as a consequence of the synergistic faradic contributions of both

${ }^{a}$ Collaborative Innovation Centre of Henan Province for Green Manufacturing of Fine Chemicals, Key Laboratory of Green Chemical Media and Reactions, Ministry of Education, School of Chemistry and Chemical Engineering, Henan Normal University, Xinxiang, Henan 453007, China. E-mail: huchengzhang66@163.com; jwang@htu.edu.cn

${ }^{b}$ School of Biological and Chemical Engineering, Nanyang Institute of Technology, Nanyang, Henan 473004, China

$\dagger$ Electronic supplementary information (ESI) available. See DOI: 10.1039/c8ra09128e metallic elements. Metal tungstates $\left(\mathrm{MWO}_{4}\right.$, where $\mathrm{M}=\mathrm{Co}, \mathrm{Ni}$, $\mathrm{Zn}, \mathrm{Cu}, \mathrm{Fe}, \mathrm{Ca}, \mathrm{Sr}$ and $\mathrm{Ba}$ ) represent a new class of semiconductor materials with excellent optical, electrical and sensor properties. ${ }^{12,13}$ Among these tungstates, $\mathrm{NiWO}_{4}, \mathrm{CoWO}_{4}$ and $\mathrm{Bi}_{2} \mathrm{WO}_{6}$ have gained considerable attention due to the excellent faradic activities and therefore energy storage capacities. ${ }^{14-17}$

The synthesis strategies of $\mathrm{MWO}_{4}$ mainly include the hydrothermal method, ${ }^{16,18,19}$ coprecipitation, ${ }^{15}$ solvothermal method, ${ }^{12,20}$ electrochemical deposition, ${ }^{14,21}$ microemulsionmediated synthesis and other methods. ${ }^{22}$ By co-precipitation reaction, spherical $\mathrm{NiWO}_{4}$ composed of nanocrystals with average grain size about $10-40 \mathrm{~nm}$ were prepared..$^{23,24}$ Using PEG or CTAB microemulsion as template, spherical $\mathrm{NiWO}_{4}$ architecture composing of primary nanocrystals were successfully formed. ${ }^{25}$ Assisted by polyethylene glycol (PEG) and triblock copolymer (pluronic 123) templates, wolframite structured $\mathrm{NiWO}_{4}$ nanocrystalline can be yielded. ${ }^{26}$ Templated by 3 -(trimethoxysilyl) propyl hexadecyl dimethyl ammonium chloride (TPHAC), mesoporous nickel tungstate $\left(m-\mathrm{NiWO}_{4}\right)$ with quasispherical morphology could be formed via hydrothermal reaction. ${ }^{19}$ Besides, octahedron $\mathrm{NiWO}_{4}$ nanocrystals with average crystallite size of $2.0 \pm 0.1 \mu \mathrm{m}$ can be facilely harvested by hydrothermal route. ${ }^{27}$

Different morphologies of $\mathrm{NiWO}_{4}$ can be prepared onto various substrates. Self-assembled $\mathrm{NiWO}_{4}$ nano-nests grown on a Ti substrate with perfect single-crystalline structure were synthesized by a hydrothermal process. ${ }^{28}$ Amorphous $\mathrm{NiWO}_{4}$ nanostructures with burl-like morphologies were successfully synthesized on a flexible conductive fabric (CF) substrate 
adhered seed-coated, which exhibited remarkable electrochemical properties with high specific capacitance $\left(1190.2 \mathrm{~F} \mathrm{~g}^{-1}\right.$ at $\left.2 \mathrm{~A} \mathrm{~g}^{-1}\right)$, excellent cyclic stability ( $92 \%$ at $\left.10 \mathrm{~A} \mathrm{~g}^{-1}\right)$, and good rate capability $\left(765.7 \mathrm{~F} \mathrm{~g}^{-1}\right.$ at $\left.20 \mathrm{~A} \mathrm{~g}^{-1}\right)$ in $1 \mathrm{M} \mathrm{KOH}$ electrolyte solution. ${ }^{14}$ Loose $3 \mathrm{D}$ network structure formed by the overlap of $\mathrm{NiWO}_{4}$ nano-particles and rGO sheet was successfully synthesized through solvothermal method, which provided a fast path for the transport of electrolyte ions, and thus facilitated the redox reaction..$^{20}$ Carbon fibre was used to synthesized 3D structure of $\mathrm{NiWO}_{4} / \mathrm{Ni} /$ carbon fibre composite by combination of electrospinning with spray deposition and subsequent carbonization, which showed excellent capacity and cyclability. ${ }^{29}$

Although much progress has been made recently, the rational construction of $\mathrm{NiWO}_{4}$ with tailored architecture with high electrons/ions mobilities still remains to be the major research topic for sake of obtaining desired applicational performances. In this work, ethylene glycol was used to fabricate nanostructures by forming glycolate precursors because of its coordination interaction with transition metal ions. In absence of substrate, the $\mathrm{NiWO}_{4}$ nanowires were fabricated by a facile solvothermal reaction with ethylene glycol as solvent. The faradic electrode based on the as-prepared $\mathrm{NiWO}_{4}$ nanowires could offer high specific capacitance, excellent rate capability and good cycling performance.

\section{Experimental}

\subsection{Materials}

$\mathrm{Na}_{2} \mathrm{WO}_{4} \cdot 2 \mathrm{H}_{2} \mathrm{O}(99 \%), \mathrm{NiCl}_{2} \cdot 6 \mathrm{H}_{2} \mathrm{O}(>97 \%$, Macklin), ethylene glycol $\left(\left(\mathrm{CH}_{2} \mathrm{OH}\right)_{2}\right)$, potassium hydroxide $(\mathrm{KOH})$, polytetrafluoroethylene emulsion (PTFE, mass percent $=60 \%$ ), activated carbon, nickel foam and all other reagents were purchased from Shanghai macklin Biochemical Co., Ltd. All reagents were used without further purification.

\subsection{Synthesis of $\mathrm{NiWO}_{4}$ nanowires}

Ethylene glycol was used solvent and ligand for preparation of $\mathrm{NiWO}_{4}$ nanowires. In brief, $2 \mathrm{mmol} \mathrm{NiCl} 2 \cdot 6 \mathrm{H}_{2} \mathrm{O}$ was dissolved into $35 \mathrm{ml}$ ethylene glycol with vigorous stirring to form a transparent solution. Subsequently, $2 \mathrm{mmol} \mathrm{Na}_{2} \mathrm{WO}_{4} \cdot 2 \mathrm{H}_{2} \mathrm{O}$ was added into form transparent reaction mixture. The obtained homogeneous solution was then transferred into a $50 \mathrm{~mL}$ Teflon-lined stainless steel autoclave and maintained at $180^{\circ} \mathrm{C}$. After being cooled to room temperature, the resulting product was rinsed repeatedly with deionized water and vacuumly dried overnight at $60{ }^{\circ} \mathrm{C}$. The products prepared at different hydrothermal time were denoted as $\mathrm{NiWO}_{4}-8, \mathrm{NiWO}_{4}-12, \mathrm{NiWO}_{4}-18$, $\mathrm{NiWO}_{4}-24$, respectively, of which the suffix represent the hydrothermal duration, e.g. the $\mathrm{NiWO}_{4}-8$ stands for the product hydrothermally reacted for $8 \mathrm{~h}$.

\subsection{Characterizations}

The chemical structure of composites were observed by X-ray diffraction (XRD, X'Pert PRO MPD, $\mathrm{Cu} \mathrm{K} \alpha \mathrm{l}=1.54 \AA$ ) and Xray photoelectron spectroscopy (XPS, Kratos Amicus X-ray photoelectron spectrometer with $\mathrm{Mg}$ Ka radiation under $2 \times$ $10^{-6} \mathrm{~Pa}$ ). The samples were measured from 10 to $80^{\circ}(2 \theta)$ with steps of $4^{\circ} \mathrm{min}^{-1}$. The morphologies characteristics of composites were analyzed by field emission scanning electron microscopy (SEM), using a FEI Quanta 600 FEG system operated at $20 \mathrm{kV}$ and transmitting electron microscopy (TEM), using a FEI Tecnai TF20 electron microscope by placing drops of the aqueous suspension onto copper grids. Nitrogen adsorption and desorption experiments were performed at $77 \mathrm{~K}$ on a SSA2000 system.

\subsection{Electrochemical measurements}

The electrochemical properties of the composites were evaluated by cyclic voltammetry (CV), galvanostatic charge-discharge (GCD) tests, and electrochemical impedance spectroscopy (EIS) on an electrochemical workstation (CHI660E, Chenhua). The working electrode was fabricated by mixing the active material, carbon black, and PTFE with a mass ratio of $75: 15: 10$, which were coated onto a Ni foam $(1 \mathrm{~cm} \times 1 \mathrm{~cm} \times 0.2 \mathrm{~cm})$. The electrode was drying at $60{ }^{\circ} \mathrm{C}$ for $12 \mathrm{~h}$. The loading mass of active material was $\sim 2 \mathrm{mg} \mathrm{cm}^{-2}$. $\mathrm{Hg} / \mathrm{HgO}$ electrode, platinum plate $(1 \mathrm{~cm} \times 1 \mathrm{~cm})$ and active materials were served as the reference electrode, counter electrode and working electrode, respectively. The electrochemical tests were performed in an aqueous electrolyte of $6 \mathrm{M} \mathrm{KOH}$, within a potential window from 0 to $0.5 \mathrm{~V}$. CVs were recorded in potential scan rate range of 5$100 \mathrm{mV} \mathrm{s}^{-1}$. EISs were recorded over $10^{5}$ to $0.01 \mathrm{~Hz}$ with an amplitude of the applied potential of $5 \mathrm{mV}$ at the open circuit potential. The average specific capacitance $\left(C_{\mathrm{s}}\right)$ was estimated from the discharge slope according to the following equation: $C_{\mathrm{s}}=I \Delta t / m \Delta V$, where $I$ is the discharge current (A), $\Delta t$ the discharge time (s), $m$ the mass of active material on work electrode $(\mathrm{g})$ and $\Delta V(\mathrm{~V})$ the discharge voltage rage. The specific capacitance of the ASC $\left(C_{\text {cell }}\right)$, energy and power density were calculated respectively according to the following equations:

$$
\begin{gathered}
C_{\mathrm{cell}}=I \Delta t / m^{\prime} V \\
E=C_{\mathrm{cell}} V / 7.2 \\
P=3600 E / \Delta t
\end{gathered}
$$

where $m^{\prime}(\mathrm{g})$ is the total mess of electroactive materials in the positive and negative electrode, $V(\mathrm{~V})$ is potential window, $E$ ( $\left.\mathrm{W} \mathrm{h} \mathrm{kg}^{-1}\right)$ is the energy density, $P\left(\mathrm{~W} \mathrm{~kg}^{-1}\right)$ is the average power density.

\section{Results and discussion}

\subsection{Characterizations of $\mathrm{NiWO}_{4}$ nanostructure}

$\mathrm{NiWO}_{4}$ nanowires were prepared through a facile equimolar reaction between $\mathrm{Na}_{2} \mathrm{WO}_{4} \cdot 2 \mathrm{H}_{2} \mathrm{O}$ and $\mathrm{NiCl}_{2} \cdot 6 \mathrm{H}_{2} \mathrm{O}$ by solvothermal method free of any further annealing. Using ethylene glycol as solvent and ligand, glycolate precursors of $\mathrm{Ni}$ was formed through the coordination interaction, which is imagined to govern the release of $\mathrm{Ni}$ source and manipulate the final morphology of the resulted $\mathrm{NiWO}_{4}$ product. Fig. 1 outlines the 


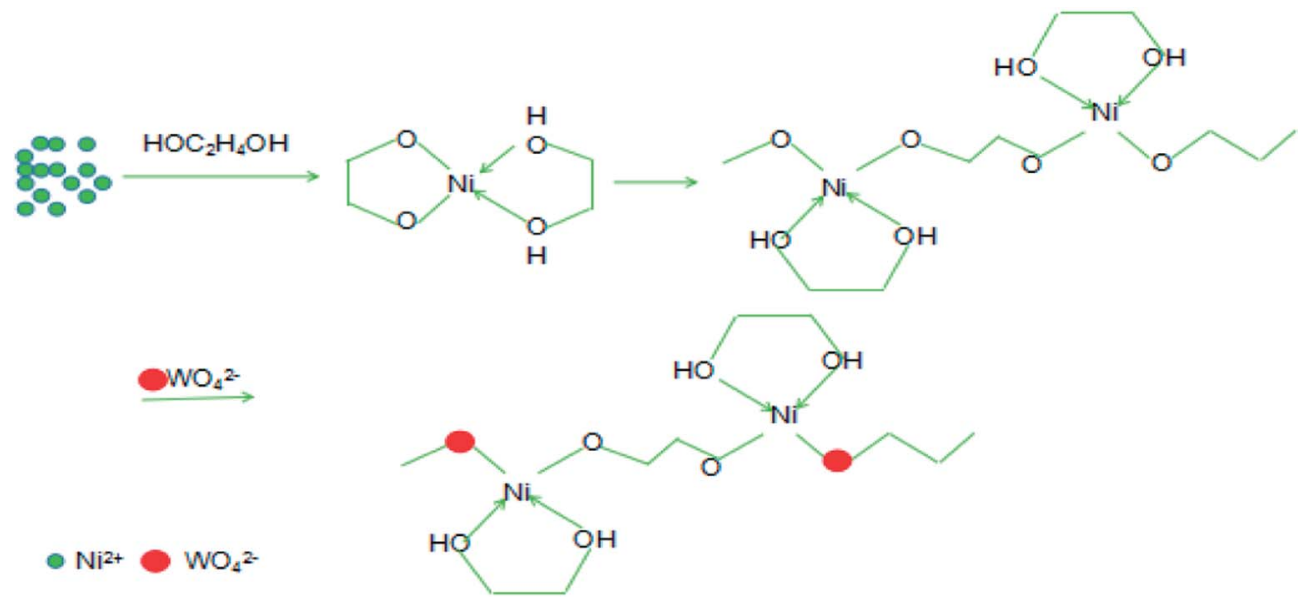

Fig. 1 Schematic illustration of the formation of $\mathrm{NiWO}_{4}$ nanowires.

plausible mechanism for the formation of $\mathrm{NiWO}_{4}$ nanowires. Ethylene glycol is a dihydric alcohol, the two hydroxyl groups can serve as chelation ligands to form O-heterocyclic $\mathrm{Ni}$ complex through $\mathrm{Ni}-\mathrm{O}$ coordination bonds when $\mathrm{Ni}$ salt was dissolved in ethylene glycol. Undergoes solverthermal reaction at elevated temperature, the partial dissociation of $\mathrm{Ni}-\mathrm{O}$ bond and the interlinking of adjacent complex units lead to the linear configuration of the Ni-glycolate coordination polymer precursors. Given the fact that hydroxyl group is not the most stable ligand for $\mathrm{Ni}^{2+}$ cation, the incorporated $\mathrm{WO}_{4}{ }^{2-}$ anions can react with the central $\mathrm{Ni}^{2+}$ cation by replacing of partial hydroxyl ligands through competitive reaction, thus primary $\mathrm{NiWO}_{4}$ nucleus were formed onto the coordination polymer chains. Undergoes the continued solvothermal process, the further aggregation, growth and the condensation of primary $\mathrm{NiWO}_{4}$ crystallites result in the linear morphology of the resultant $\mathrm{NiWO}_{4}$ product. In this solvothermally formation and growth procedure, the immature structure or the overcondensation may influence the final morphology and the surface utilization ratio of the $\mathrm{NiWO}_{4}$ product, the aging time is a significant parameter need to be well controlled. Considering the intrinsically high conductivity of $\mathrm{NiWO}_{4}\left(10^{-7}\right.$ to $10^{-3} \mathrm{~S} \mathrm{~cm}^{-1}$ at different temperatures), ${ }^{30}$ the linear structure with efficient electrons migration channel, as well as the faradic activity of $\mathrm{Ni}$ element, high faradic capacitance can be ensured when employed as electrode material of supercapacitor.

Fig. 2a shows the XRD pattern of the typical $\mathrm{NiWO}_{4}-12$ sample, as seen, the XRD pattern comprises a series of
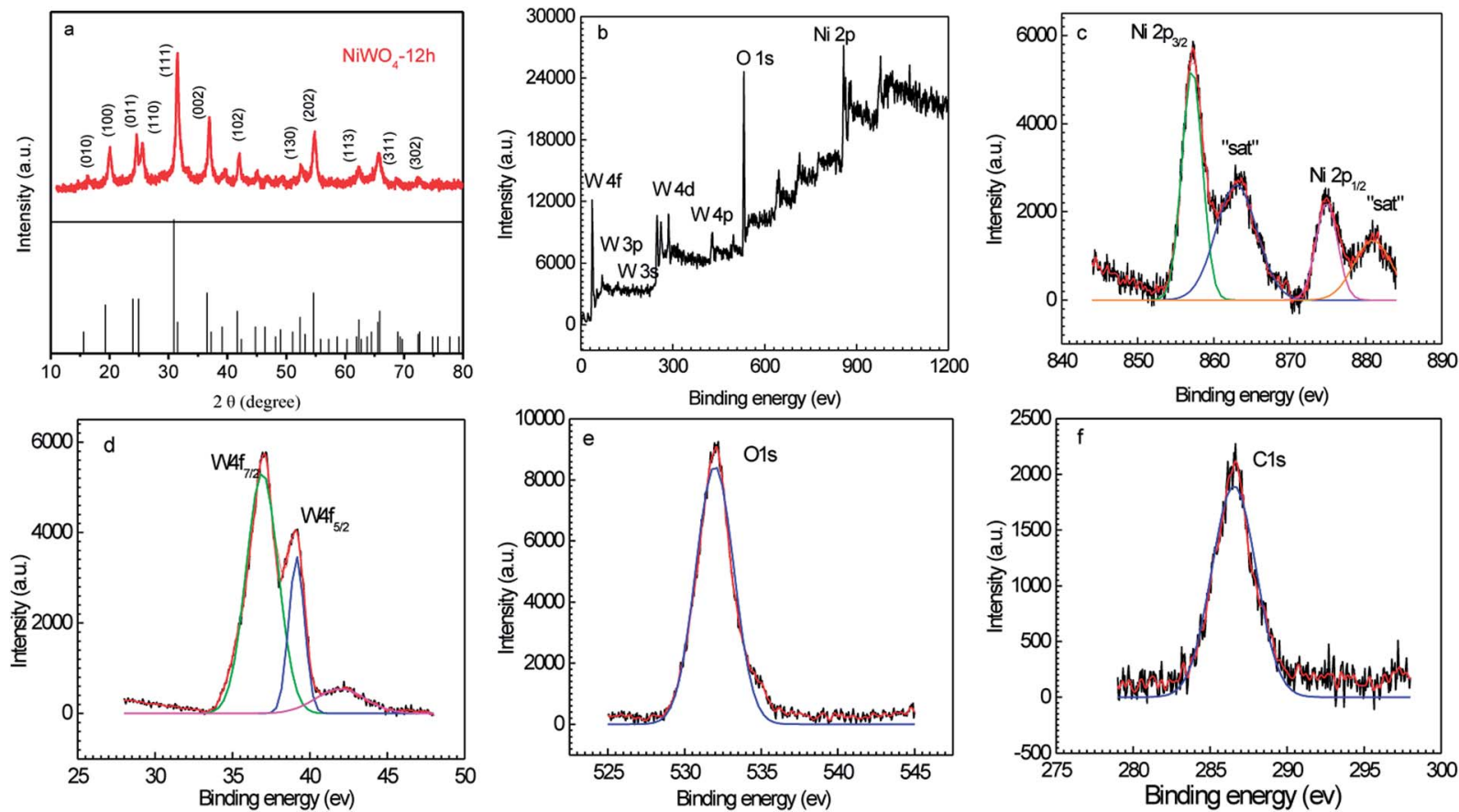

Fig. 2 XRD patterns (a) and XPS spectra of $\mathrm{NiWO}_{4}-12$ sample (b-f). 
diffraction peaks located at $15.6^{\circ}, 19.27^{\circ}, 23.96^{\circ}, 24.9^{\circ}, 30.9^{\circ}$, $36.5^{\circ}, 41.6^{\circ}, 52.3^{\circ}, 54.6^{\circ}, 62.3^{\circ}, 65.8^{\circ}$, and $72.6^{\circ}$, which are corresponded respectively to the (010), (100), (011), (110), (111), (002), (102), (130), (202), (113), (311), and (302) crystallographic planes of $\mathrm{NiWO}_{4}$ (JCPDS\# 15-0755). ${ }^{\mathbf{1 4}}$ The surface bonding and element oxidation states of the $\mathrm{NiWO}_{4}$ samples were further characterized by XPS and the results were shown in Fig. $2 b-f$. As observed in Fig. 2b, the XPS survey scan spectrum indicates the presence of elemental $\mathrm{Ni}, \mathrm{W}, \mathrm{O}$, and $\mathrm{C}$ according to their respective binding energies. The high-resolution $\mathrm{Ni} 2 \mathrm{p}, \mathrm{W} 4 \mathrm{f}$, and $\mathrm{O}$ 1s spectral curves were fitted well with the Gaussian curves as shown in Fig. 2c-e. From Fig. 2c, the Ni 2p spectrum mainly includes the spin orbit doublets of the $\mathrm{Ni} 2 \mathrm{p}_{3 / 2}$ and $\mathrm{Ni}$ $2 \mathrm{p}_{1 / 2}$ orbits at binding energies of 857.1 and $874.8 \mathrm{eV}$, respectively, as well as two shake-up satellite peaks, all of these features indicates the $\mathrm{Ni}$ elements mainly in form of $\mathrm{Ni}$ (II) oxidation value. ${ }^{31}$ These results reveal that the Ni species are in the +2 oxidation state. Meanwhile, the high resolution XPS spectrum of $\mathrm{W}$ 4f showed spin-orbit splitting of $\mathrm{W} 4 \mathrm{f}_{7 / 2}$ at $37.0 \mathrm{eV}$ and $\mathrm{W} 4 \mathrm{f}_{5 / 2}$ at $39.1 \mathrm{eV}$, implying that the $\mathrm{W}$ is in the +6 oxidation state in the prepared product. The $\mathrm{O} 1 \mathrm{~s}$ spectrum with a binding energy value of $532.0 \mathrm{eV}$ was associated with the lattice O-bond with the $\mathrm{W}$ and $\mathrm{Ni}$ in $\mathrm{NiWO}_{4} \cdot{ }^{32,33}$ To be mentioned, the weak $\mathrm{C} 1 \mathrm{~s}$ peak is presumably derived from the incompletely rinced ethylene glycol molecules. The XPS, along with that of the XRD results evidence the successful formation of $\mathrm{NiWO}_{4}$ by solverthermal reaction.

Fig. 3 presents the TEM images of the $\mathrm{NiWO}_{4}$ samples synthesized for different solvothermal time. As depicted in Fig. 3a, the $\mathrm{NiWO}_{4}-8$ sample exhibits nanowires with an average diameter of $35 \mathrm{~nm}$ and average length of $3.3 \mu \mathrm{m}$, enlarged TEM image reveals that the nanowire is composed of stacked primary particles, which manifest the conversion and aggregation of $\mathrm{NiWO}_{4}$ particles from the linear $\mathrm{Ni}$ glycolate precursors. Undergoes prolonged solvothermal time course, the $\mathrm{NiWO}_{4}-12$ sample (Fig. 3b) exhibits the similar morphology, but the seemingly enlarged size of the primary particles and the enlarged inter-particle void suggest the more sufficient crystallization of the primary particles, the enlarged voids allows the more easily accessible of electrolyte and enhanced surface utilization ratio, which is especially beneficial for surface related applications. In the cased of $\mathrm{NiWO}_{4}-18$ prepared at more longer solvothermal reaction time (Fig. 3c), the sample displays irregularly intertwined nanowires with shorter length, which indicated the excessive solvothermal reaction causes the unreasonable condensation of the nanowires. The further prolonging of reaction time causes the further aging and the destroying of the nanowires, as shown in Fig. 3d, the $\mathrm{NiWO}_{4}-24$ mainly exhibits stacked short nanowires and particles with more ill-defined morphology, which manifest the excess solvothermal time is really disadvantageous for the nanowire morphology. Therefore, it could be concluded that the size and morphology of the precursor was significantly changed over reaction time. The morphological evolution of $\mathrm{NiWO}_{4}$ samples evidence the procedure in schematic illustration in Fig. 1, namely, the nanocrystal nucleies initially formed along the linear precursor, the subsequent aging caused the stacking and growing into nanowires, the overcondensation deteriorated the $\mathrm{NiWO}_{4}$ nanowires morphology.

Furthermore, Brunauer-Emmett-Teller (BET) analyses were further performed to evaluate the surface area and pore size distribution of the $\mathrm{NiWO}_{4}$ samples. It could be observed in Fig. $4 \mathrm{a}$, the isotherm of $\mathrm{NiWO}_{4}-12$ sample showed typical IV adsorption-desorption isotherms with a hysteresis in the range
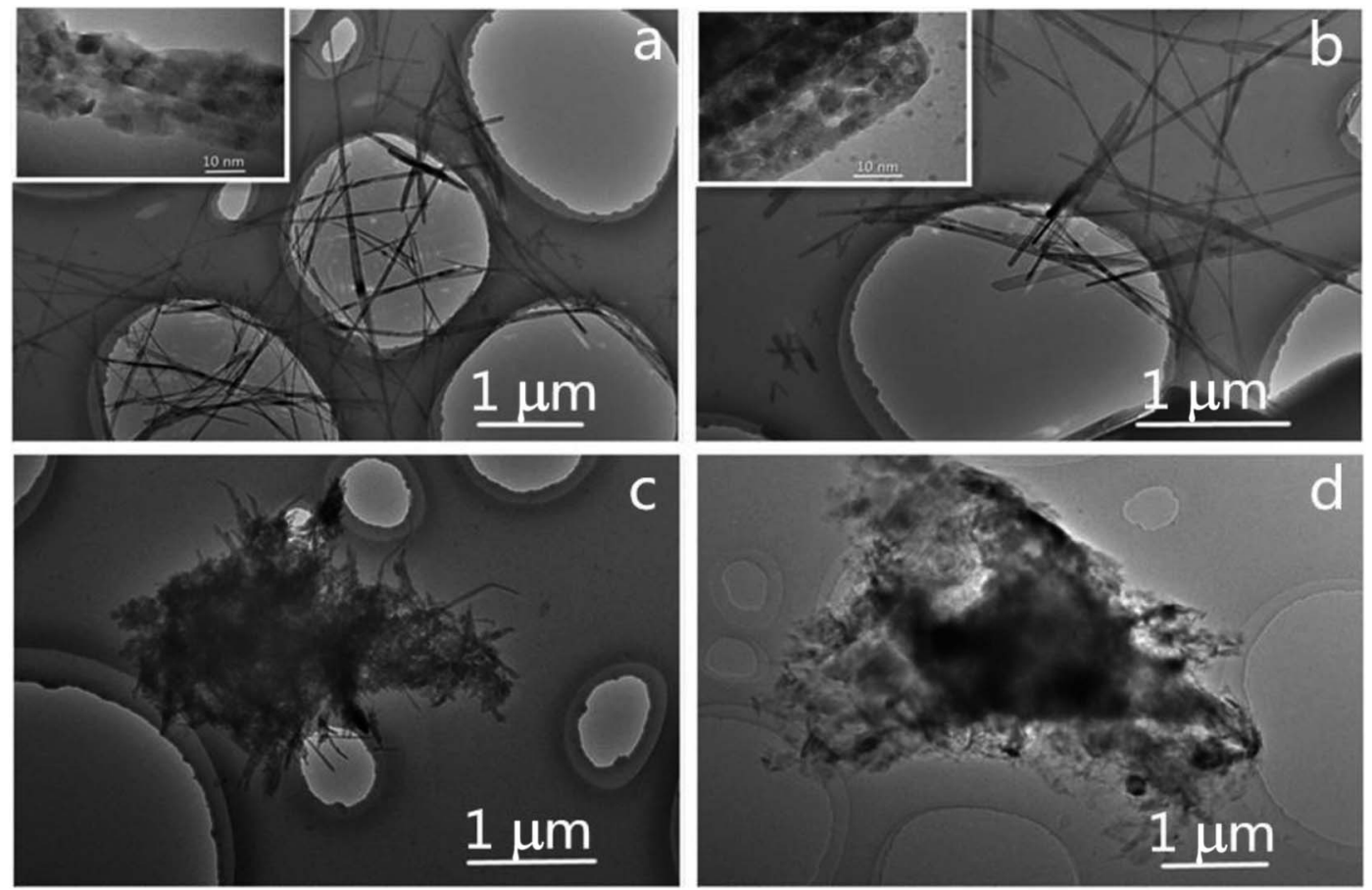

Fig. 3 TEM of the $\mathrm{NiWO}_{4}$ samples prepared at different solvothermal time (a) $\mathrm{NiWO}_{4}-8$, (b) $\mathrm{NiWO}_{4}-12$, (c) $\mathrm{NiWO}_{4}-18$, (d) $\mathrm{NiWO}_{4}-24$. 

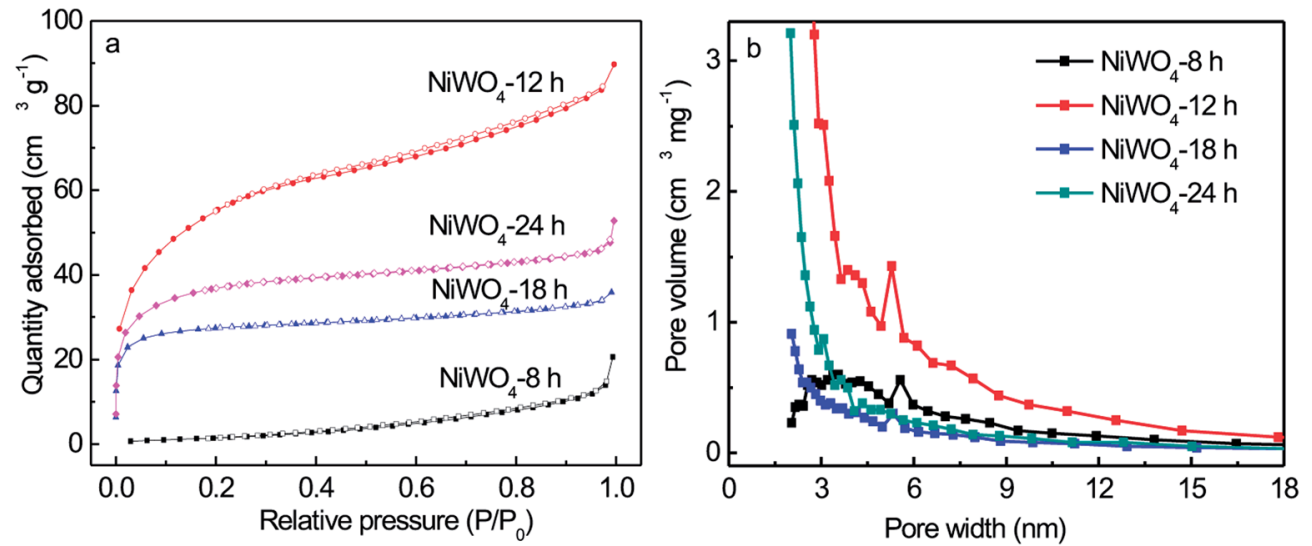

Fig. $4 \mathrm{~N}_{2}$ adsorption-desorption isotherm (a), and pore size distribution (b) of $\mathrm{NiWO}_{4}$ samples prepared for different solvothermal time.

of 0.4-1.0 $P / P_{0}$, indicating the presences of mesopores and macropores possibly formed by the loose stacking of constituent $\mathrm{NiWO}_{4}$ nanowires. The isotherm of $\mathrm{NiWO}_{4}{ }^{-8}, \mathrm{NiWO}_{4}-18$ and $\mathrm{NiWO}_{4}-24$ samples showed typical I adsorption-desorption isotherms, indicating mainly consists of microporous structure.
The obtained $\mathrm{NiWO}_{4}-12$ sample was further confirmed by the pore size distribution at 3 to $7 \mathrm{~nm}$ and the calculated surface area was $199.7 \mathrm{~m}^{2} \mathrm{~g}^{-1}$. The BET specific surface area and the Barrett-Joyner-Halenda (BJH) desorption pore volumes of all $\mathrm{NiWO}_{4}$ samples were listed in Table S1. $\dagger$ The corresponding
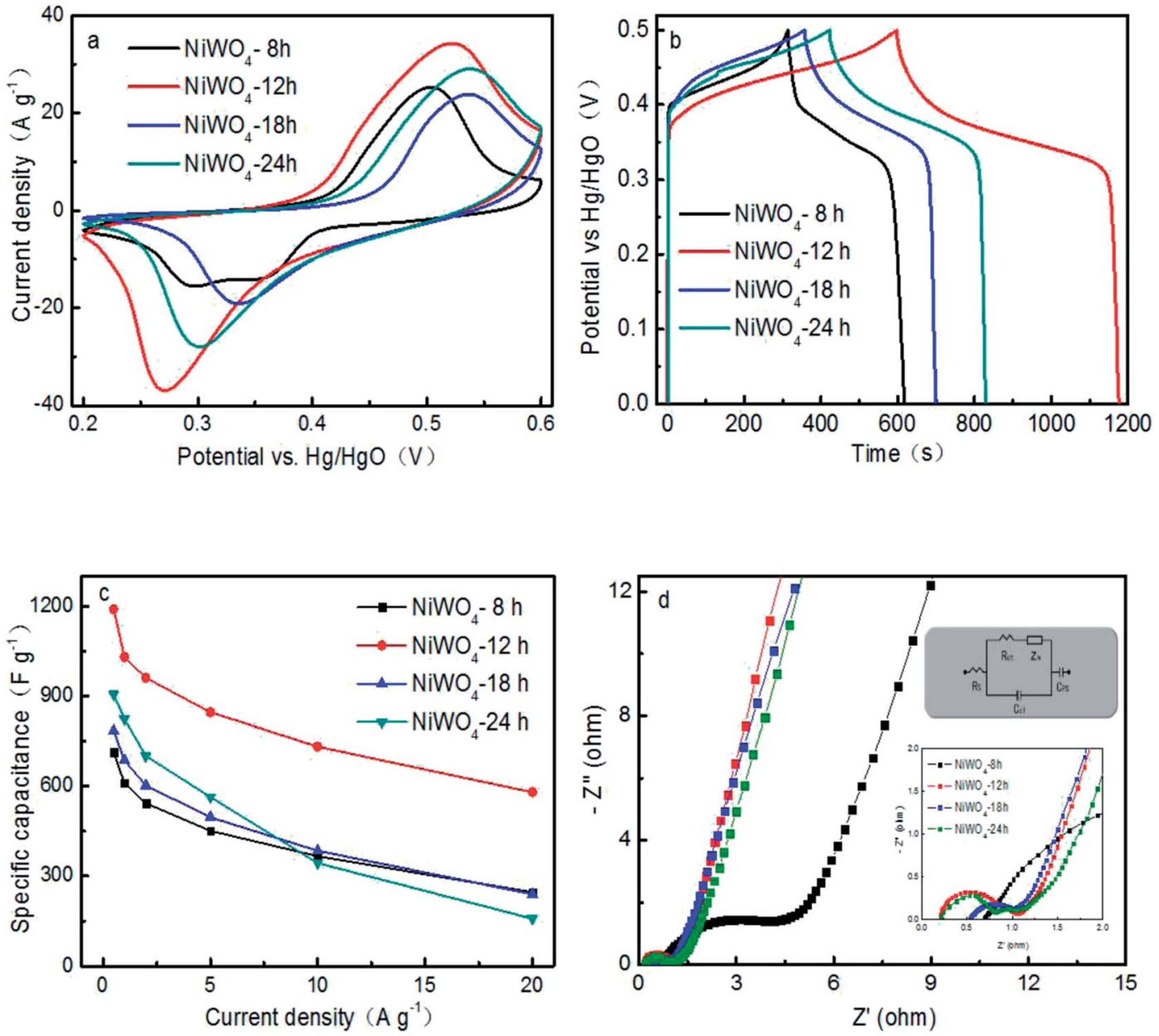

Fig. 5 (a) CV curves at a scan rate of $10 \mathrm{mV} \mathrm{s}^{-1}$, (b) charging and discharging curves at $1 \mathrm{~A} \mathrm{~g}^{-1}$, (c) specific capacitance at different discharging currents density, and (d) EISs and inset for the equivalent circuit of $\mathrm{NiWO}_{4}$ samples prepared for different hydrothermal time in 6 mol $\mathrm{L}^{-1} \mathrm{KOH}^{-}$ electrolyte. 
$\mathrm{BJH}$ pore size distribution curves revealed that the pore size distributions were non-uniform within the range of mesopores and macropores displayed in Fig. $4 \mathrm{~b}$.

\subsection{Electrochemical performances of the $\mathrm{NiWO}_{4}$ samples}

In order to assess the feasibility of the fabricated $\mathrm{NiWO}_{4}$ in faradic electrode of supercapacitor, $\mathrm{CV}$ curves at a scan rate of $10 \mathrm{mV} \mathrm{s}^{-1}$ within the electrochemical window from $0.2 \mathrm{~V}$ to $0.6 \mathrm{~V}$ were carried out and the corresponding CVs were shown in Fig. 5a. Obviously, the shapes of CV curves were evidently different from that of EDLCs which were similar to an idea rectangular shape. All CV curves comprise a pair of well-defined redox peaks, suggesting that the measured capacitances were mainly governed by the faradaic redox mechanism. The current peaks were based on the reversible reactions of $\mathrm{Ni}^{2+}$ to $\mathrm{Ni}^{3+} \cdot{ }^{15}$ Moreover, the integral area of $\mathrm{NiWO}_{4}-12$ is the largest, following with the $\mathrm{NiWO}_{4}-24, \mathrm{NiWO}_{4}-18$ and $\mathrm{NiWO}_{4}-8$. Fig. 5b exhibited the GCD curves of $\mathrm{NiWO}_{4}$ prepared for different hydrothermal time with as-triangular shape at $1 \mathrm{~A} \mathrm{~g}^{-1}$, due to the pseudocapacitance of reaction between $\mathrm{Ni}$ (II) and $\mathrm{Ni}$ (III), which was coincident with the CV curves. The specific capacitances of all samples calculated from the discharge curves at $1 \mathrm{~A} \mathrm{~g}^{-1}$ were presented in Fig. $5 \mathrm{c}$. $\mathrm{NiWO}_{4}-12$ electrode exhibited the highest specific capacitance, which could be achieved $1190 \mathrm{~F} \mathrm{~g}^{-1}$ at a current density of $0.5 \mathrm{~A} \mathrm{~g}^{-1}$ and 1030, 960.8, 864, 732 and 580 $\mathrm{F} \mathrm{g}^{-1}$ at current density of $1,2,5,10$ and $20 \mathrm{~A} \mathrm{~g}^{-1}$, respectively. Obviously, the specific capacitance of $\mathrm{NiWO}_{4}$ electrodes decreased with the increase of current density, which derived from the insufficient ion diffusion. The specific capacitance of $\mathrm{NiWO}_{4}-24$ was higher than that of $\mathrm{NiWO}_{4}-18$ and $\mathrm{NiWO}_{4}-8$.

EIS measurements were also carried out to evaluate the charge transfer and electrolyte diffusion in the electrode/ electrolyte interface, as shown in Fig. 5d. Obviously, the EIS of $\mathrm{NiWO}_{4}$ electrode was composed of a semicircle at the highfrequency region and a straight line at the low-frequency region. ${ }^{34}$ It could be observed all plots reveal similar shape. The intercept at real axis $\left(Z^{\prime}\right)$ refers to the equivalent series resistance $\left(R_{\mathrm{s}}\right)$, which mainly consists of the inherent resistance of the electrode materials, the electrolyte solution resistance, and the contact resistance at the interface. ${ }^{35}$ The $R_{\mathrm{S}}$ of $\mathrm{NiWO}_{4}-12$ $(0.22 \Omega)$ was lower than those of $\mathrm{NiWO}_{4}-24(0.27 \Omega), \mathrm{NiWO}_{4}-18$
$(0.52 \Omega)$ and $\mathrm{NiWO}_{4}-8(0.71 \Omega)$, indicating that the low internal resistance and considerably outstanding conductivity. ${ }^{36}$ At the high frequency range, a small semicircle can be obviously observed, the diameter reflects the charge-transfer resistance $\left(R_{\mathrm{ct}}\right)$ and derives from the double-layer capacitance and faradic reaction at electrode/electrolyte interface. Among all the samples, $\mathrm{NiWO}_{4}-12$ and $\mathrm{NiWO}_{4}-24$ exhibited the small values of $R_{\text {ct }}(0.43 \Omega$ and $0.46 \Omega)$ at high frequency, implying the low charge transfer and diffusion resistance and fastest ion diffusion. Moreover, at the low frequencies, the slop of Nyquist plot curves of the $\mathrm{NiWO}_{4}-12$ was larger than that of $\mathrm{NiWO}_{4}-8$, $\mathrm{NiWO}_{4}-18$ and $\mathrm{NiWO}_{4}-24$, indicating its ideal capacitance performance. The high electrochemical performance, good conductivity of $\mathrm{NiWO}_{4}-12$ was attributed to minimize diffusion resistance to mass transport at the electrode/electrolyte interface for the smaller size using suitable solvents in solvothermal synthesis.

To further verify the pseudocapacitance contribution, typical CV curves of $\mathrm{NiWO}_{4}$ samples prepared using ethylene glycol as solvent at a variety of scan rates varying from 5 to $100 \mathrm{mV} \mathrm{s}^{-1}$ were shown in Fig. 6a. All CV curves exhibited a pair of welldefined redox peaks, signifying typical pseudocapacitive behavior. Moreover, the integral area $\mathrm{CV}$ curves of $\mathrm{NiWO}_{4}$ samples increased with the increase of the scan rates, and rapid current response on voltage reversal occured at each end potential, revealing its good electrochemical capacitance. Fig. $6 \mathrm{~b}$ exhibited the GCD curves of $\mathrm{NiWO}_{4}$ with as-triangular shape at different current densities, due to the pseudocapacitance of reaction between $\mathrm{Ni}(\mathrm{II})$ and $\mathrm{Ni}(\mathrm{III})$, which was coincident with the CV curves. It was shown that the peak current $\left(i_{\mathrm{p}}\right)$ in CVs increase with the increase of scan rate $(\nu)$, and followed a linear equation: $\log i_{\mathrm{p}}=0.67427 \log \nu+1.1022\left(R^{2}=0.9993\right.$, Fig. $6 \mathrm{c})$. The linear slope closes to 0.5 , indicated that the charge storage process is controlled by the bulk diffusion of electrolyte ions.

\subsection{Electrochemical performances of the $\mathrm{NiWO}_{4} / / \mathrm{AC}$ ASC}

To obtain a high energy density, ASC was face-to-face assembled using $\mathrm{NiWO}_{4}$ nanowires and $\mathrm{AC}$ as cathode and anode electrodes with a cellulose paper sandwiched between them (Fig. 8). The assembly was immersed into $6 \mathrm{M} \mathrm{KOH}$ aqueous solution.
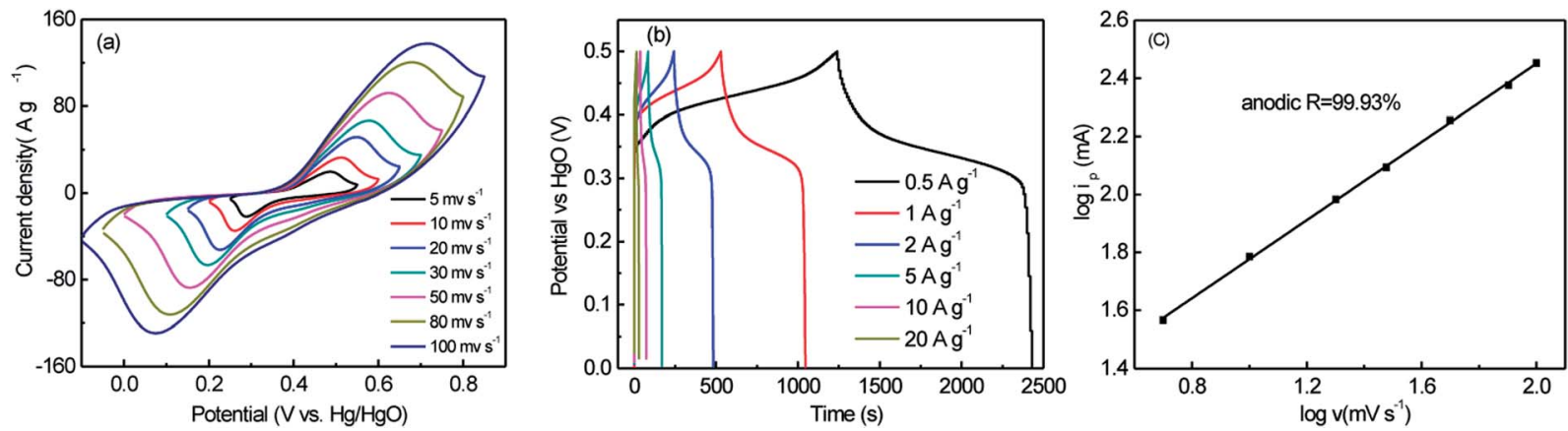

Fig. $6 \mathrm{CV}$ curves at different scan rate (a), charging and discharging curves at $1 \mathrm{~A} \mathrm{~g}^{-1}$ (b), and dependence of cathodic peak current on scan rate (c) of $\mathrm{NiWO}_{4}-12$ in $6 \mathrm{~mol} \mathrm{~L}^{-1} \mathrm{KOH}$ electrolyte. 

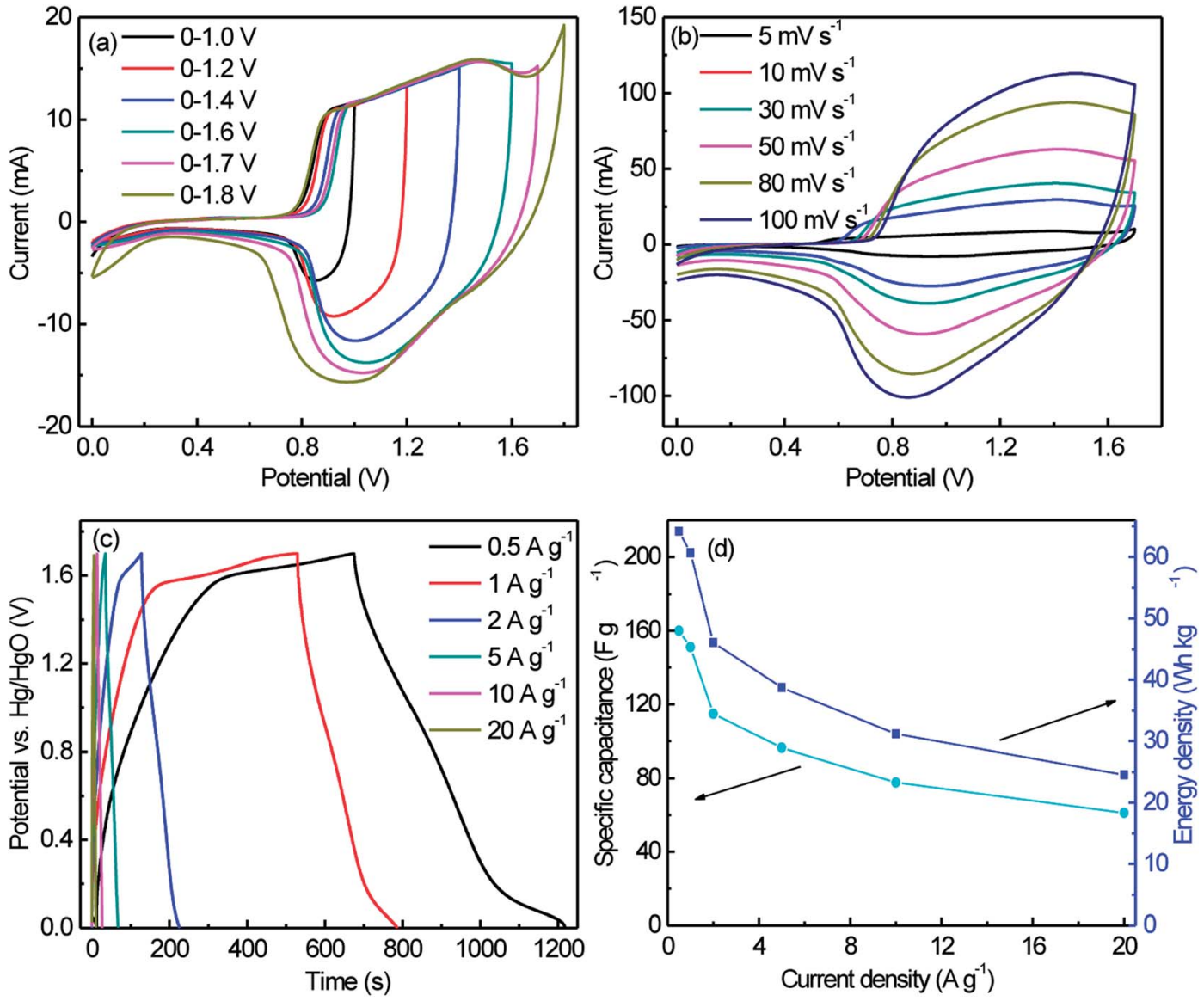

Fig. $7 \mathrm{CV}$ curves measured at $10 \mathrm{mV} \mathrm{s}^{-1}$ with different potential windows (a), CV curves measured at different scan rates (b), GCD curves measured at different current densities between 0 and $1.7 \mathrm{~V}$ (c), and the specific capacitance and energy density calculated from discharge curves at different current density (d) of $\mathrm{NiWO}_{4} / / \mathrm{AC}$ ASC in $6 \mathrm{M} \mathrm{KOH}$ aqueous electrolyte.

The mass ratio of active materials on cathode electrode $\left(\mathrm{m}^{+}\right)$to anode electrode $\left(\mathrm{m}^{-}\right)$was set at 0.4 to match the charges according to the equation $\mathrm{m}^{+} / \mathrm{m}^{-}=\mathrm{C}^{-} / \mathrm{C}^{+}$, where $\mathrm{C}^{+}$and $\mathrm{C}^{-}$ respectively are the specific capacities of $\mathrm{NiWO}_{4}$ and activated carbon.

Fig. 7a gives CV curves of the $\mathrm{NiWO}_{4} / / \mathrm{AC}$ ASC at different potential windows in $6 \mathrm{M} \mathrm{KOH}$ aqueous solution at $10 \mathrm{mV} \mathrm{s}^{-1}$. The assembled ASC showed a broad redox peak and could be cycled between 0 and $1.7 \mathrm{~V}$ with a good reversibility. Accordingly, the potential window of $0-1.7 \mathrm{~V}$ was chosen for the following investigation of the overall electrochemical performances of the ASC. Fig. $7 \mathrm{~b}$ showed CV curves of the $\mathrm{NiWO}_{4} / / \mathrm{AC}$ ASC at different scan rates in $6 \mathrm{M} \mathrm{KOH}$ aqueous solution. Fig. 7c showed the GCD curves of the $\mathrm{NiWO}_{4} / / \mathrm{AC}$ ASC measured at different current densities in the $6 \mathrm{M} \mathrm{KOH}$ aqueous electrolyte, it could be observed that all the discharge curves were nearly symmetric with their corresponding charging counterparts, demonstrating the excellent electrochemical reversibility and good Coulombic efficiency. The specific capacitances calculated from the galvanostatic charge-discharge curves according to eqn (1) were $160,151.2,114.8,96.5,77.6$ and $61.2 \mathrm{~F} \mathrm{~g}^{-1}$, corresponding to the current densities of $0.5,1,2,5,10$ and $20 \mathrm{~A} \mathrm{~g}^{-1}$, respectively (Fig. 7d). It was clearly obtained that the capacitance decreased gradually with increase of current density, and $38.2 \%$ of capacitance was still retained when the current density increased from 0.5 to $20 \mathrm{~A} \mathrm{~g}^{-1}$, suggesting that the $\mathrm{NiWO}_{4} / / \mathrm{AC}$ ASC possessed good rate capability. The energy density of the $\mathrm{NiWO}_{4} / / \mathrm{AC}$ ASC had been shown in Fig. 7d, the

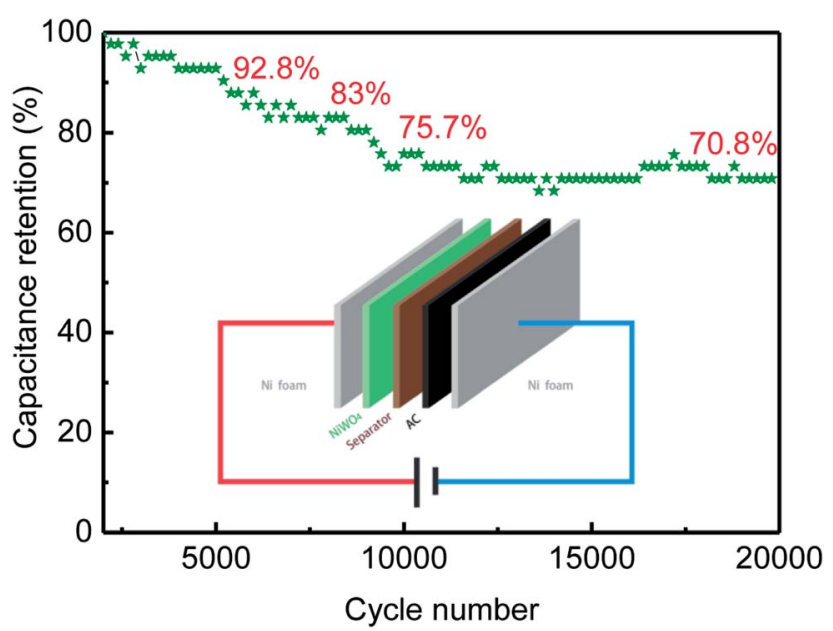

Fig. 8 Cycle life of $\mathrm{NiWO}_{4} / / \mathrm{AC}$ ASC in $6 \mathrm{M} \mathrm{KOH}$ aqueous electrolyte. 
$E_{\text {cell }}$ achieved up to $64.2 \mathrm{~W} \mathrm{~h} \mathrm{~kg}^{-1}$ at $P_{\text {cell }}$ of $450 \mathrm{~W} \mathrm{~kg}^{-1}$, and declined to $24.55 \mathrm{~W} \mathrm{~h} \mathrm{~kg}^{-1}$ with $P_{\text {cell }}$ increases to $17000 \mathrm{~W} \mathrm{~kg}^{-1}$, showing the high energy and power delivery abilities of the ASC and ranking a high level among the recently reported supercapacitors based on nanostructured $\mathrm{NiWO}_{4}$ (as the listed results shown in Table S2 $\dagger$ ).

The cycling stability of the asymmetric supercapacitor was further investigated by galvanostatic charge-discharge between 0 and $1.7 \mathrm{~V}$ at a current density of $5.0 \mathrm{~A} \mathrm{~g}^{-1}$. Results shown that the assembled supercapacitor retained $92.8 \%$ and $70.8 \%$ of initial capacitance even after 5000 and 20000 consecutive cycles of charge-discharge testing, respectively, which displayed an excellent cycling ability of $\mathrm{NiWO}_{4} / / \mathrm{AC}$ ASC. It is believed that the proper mass ratio of $\mathrm{NiWO}_{4}$ to $\mathrm{AC}$ can balance the charge storage in the positive and negative electrodes, and improve the electrochemical performances of the ASC. Based on the high energy and power delivering ability and the good cycleability, the $\mathrm{NiWO}_{4} / / \mathrm{AC}$ ASC herein could serve as an efficient and long lifetime energy storage device.

\section{Conclusions}

In summary, the $\mathrm{NiWO}_{4}$ nanowires were successfully synthesized by a simple solvothermal method with ethylene glycol as solvent in absence of substrate. The $\mathrm{NiWO}_{4}$ nanowires were applied as electrode material for supercapacitors and exhibited a high specific capacitance of $1190 \mathrm{~F} \mathrm{~g}^{-1}$ at $0.5 \mathrm{~A} \mathrm{~g}^{-1}$ in a threeelectrode system. The asymmetric supercapacitor device was successfully assembled using $\mathrm{NiWO}_{4}$ and $\mathrm{AC}$ as the cathode and anode, respectively. The device delivered a high energy density of $64.2 \mathrm{~W} \mathrm{~h} \mathrm{~kg}^{-1}$ at a power density of $425 \mathrm{~W} \mathrm{~kg}^{-1}$, and still maintained a power density of $17.0 \mathrm{~kW} \mathrm{~kg}^{-1}$ with an energy density of $24.55 \mathrm{~W} \mathrm{~h} \mathrm{~kg}^{-1}$. Furthermore, the supercapacitor also possessed an excellent long cycle life along with retained $92.8 \%$ and $70.8 \%$ of initial capacitance even after 5000 and 20000 consecutive cycles in the high-voltage region of $0-1.7 \mathrm{~V}$ at $5 \mathrm{~A} \mathrm{~g}^{-1}$. These excellent properties make $\mathrm{NiWO}_{4}$ a promising electrode material for high-performance supercapacitor applications.

\section{Conflicts of interest}

There are no conflicts to declare.

\section{Acknowledgements}

The authors gratefully acknowledge the financial support from the National Natural Science Foundation of China (Grant No. 21573059 and 21473050) and the Key Science and Technology project of Xinxiang (CXGG17001).

\section{References}

1 L. Wang, D. Wang, Z. Dong, F. Zhang and J. Jin, Nano Lett., 2013, 13, 1711-1716.

2 Y. Zhong, M. Yang, X. Zhou, Y. Luo, J. Wei and Z. Zhou, Adv. Mater., 2015, 27, 806-812.
3 Y. Zhao, J. Liu, D. Zheng, B. Wang, M. Hu, J. Sha and Y. Li, Small, 2017, 14, 1702809.

4 Q. Liu, C. Chen, J. Zheng, L. Wang, Z. Yang and W. Yang, J. Mater. Chem. A, 2017, 5, 1421-1427.

5 J. Gui, J. Zhang, T. Liu, Y. Peng and J. Chang, New J. Chem., 2017, 41, 10695-10702.

6 H. Xie, S. Tang, D. Li, S. Vongehr and X. Meng, ChemSusChem, 2017, 10, 2301-2308.

7 X. Wu, L. Meng, Q. Wang, W. Zhang and Y. Wang, Chem. Eng. J., 2017, 327, 193-201.

8 V. Veeramani, R. Madhu, S.-M. Chen, M. Sivakumar, C.-T. Hung, N. Miyamoto and S.-B. Liu, Electrochim. Acta, 2017, 247, 288-295.

9 D. Song, J. Zhu, J. Li, T. Pu, B. Huang, C. Zhao, L. Xie and L. Chen, Electrochim. Acta, 2017, 257, 455-464.

10 H. J. Kim, C. W. Kim, S. Y. Kim, A. E. Reddy and C. V. V. M. Gopi, Mater. Lett., 2018, 210, 143-147.

11 B. Saravanakumar, S. P. Ramachandran, G. Ravi, V. Ganesh, A. Sakunthala and R. Yuvakkumar, Mater. Lett., 2017, 209, 14.

12 J. Zhang, C. Xu, R. Zhang, X. Guo, J. Wang, X. Zhang, D. Zhang and B. Yuan, Mater. Lett., 2018, 210, 291-294.

13 S. M. El-Sheikh and M. M. Rashad, J. Cluster Sci., 2014, 26, 743-757.

14 G. Nagaraju, R. Kakarla, S. M. Cha and J. S. Yu, Nano Res., 2015, 8, 3749-3763.

15 X. Xu, J. Gao, G. Huang, H. Qiu, Z. Wang, J. Wu, Z. Pan and F. Xing, Electrochim. Acta, 2015, 174, 837-845.

16 A. Li, Int. J. Electrochem. Sci., 2017, 5646-5656.

17 H. Zheng, G. Yang, S. Chen and Y. Jia, ChemElectroChem, 2017, 4, 577-584.

18 X. Xing and J. Wang, J. Mater. Sci.: Mater. Electron., 2016, 27, 11613-11622.

19 M. I. Ahmed, A. Adam, A. Khan, M. N. Siddiqui, Z. H. Yamani and M. Qamar, Mater. Lett., 2016, 177, 135-138.

20 X. Xu, L. Pei, Y. Yang, J. Shen and M. Ye, J. Alloys Compd., 2016, 654, 23-31.

21 S. Chen, G. Yang, Y. Jia and H. Zheng, J. Mater. Chem. A, 2017, 5, 1028-1034.

22 J. Liu, Z. Zhang, Z. Wang, M. Tang, J. Li, J. Yi, T. Zuo, Y. Wu and Q. Ma, J. Alloys Compd., 2017, 727, 107-113.

23 V. Srirapu, A. Kumar, P. Srivastava, R. Singh and A. Sinha, Electrochim. Acta, 2016, 209, 75-84.

24 Y. Wang, C. Shen, L. Niu, Z. Sun, F. Ruan, M. Xu, S. Shan, C. Li, X. Liu and Y. Gong, Mater. Chem. Phys., 2016, 182, 394-401.

25 M. Mohamed, S. Ahmed and K. Khairou, Appl. Catal., B, 2014, 150-151, 63-73.

26 M. Masteri-Farahani and M. Saemi, J. Mater. Sci.: Mater. Electron., 2016, 28, 1328-1335.

27 S. Mani, V. Vediyappan, S. M. Chen, R. Madhu, V. Pitchaimani, J. Y. Chang and S. B. Liu, Sci. Rep., 2016, 6, 24128-24133.

28 B. Sun, W. Zhao, L. Wei, H. Li and P. Chen, Chem. Commun., 2014, 50, 13142-13145.

29 Y. He, L. Wang, D. Jia, Z. Zhao and J. Qiu, Electrochim. Acta, 2016, 222, 446-454. 
30 S. M. AlShehri, J. Ahmed, A. M. Alzahrani and T. Ahamad, New J. Chem., 2017, 41, 8178-8186.

31 Z. Gao, C. Chen, J. Chang, L. Chen, P. Wang and D. Wu, Chem. Eng. J., 2018, 343, 572-582.

32 Y. Huang, Y. Chen, X. Shi, Z. Wan, Z. Li, Y. Yan, M. Zhang and G. Cao, Nano Energy, 2018, 48, 430-440.

33 L. Niu, Z. Li, Y. Xu, J. Sun, W. Hong and X. Liu, ACS Appl. Mater. Interfaces, 2013, 5, 8044-8052.
34 J. Lang, L. Kong, W. Wu, M. Liu, Y. Luo and L. Kang, J. Solid State Electrochem., 2008, 13, 333-340.

35 X. Wei, X. Jiang, J. Wei and S. Gao, Chem. Mater., 2016, 28, 445-458.

36 Y. Wang, D. Wang, Q. Li, W. Guo, F. Zhang and Y. Yu, Part. Part. Syst. Charact., 2018, 35, 1700336. 